\title{
Os sistemas econômicos e suas formas de racionalidades: a busca das singularidades na moderna história econômica e seus novos desafios
}

\begin{abstract}
José D’Assunção Barros ${ }^{1}$
Resumo: Esse artigo, partindo de uma discussão acerca das noções de "sistema econômico" e "racionalidades econômicas", busca desenvolver algumas considerações acerca da História Econômica enquanto um campo de estudos específico no interior da historiografia profissional, bem como discutir as possibilidades e limites de aspectos metodológicos referentes a esta modalidade da História. A última parte do artigo exemplifica com a questão específica do sistema econômico em que estava alicerçada a economia colonial escravista no Brasil dos séculos XVIII e XIX.
\end{abstract}

Palavras-chave: história econômica; sistema econômico; racionalidades.

\section{Economic systems and forms of rationality: the search of singularities in modern economic history and its challenges}

\begin{abstract}
This article, after a initial discussion around the notions of "economic system" and "economic rationalities", intends to develop some considerations about the Economic History as a specifically historiographical field in the ambit of the professional historiography, and to discuss the possibilities and limits of the methodological aspects in this modality of history. The last part of the article exemplifies with the specifically question of the economic system in which one was established the colonial and slavery economy in Brazil of XVIII and XIX centuries.
\end{abstract}

Key words: economic history; economic system; economic rationalities.

JEL: B1; B13; B19.

1 Professor adjunto da Universidade Federal Rural do Rio de Janeiro (UFRRJ). Professor colaborador do Programa de Pós-Graduação em História Comparada da Universidade Federal do Rio de Janeiro (UFRJ). Doutor em História pela Universidade Federal Fluminense (UFF). E-mail: jose.assun@globo.com 


\section{Introdução}

Quais são os riscos contra os quais se defrontam, mais habitualmente, os historiadores econômicos e economistas-historiadores na análise de seus objetos de estudo? Entre estes, podem ser mencionados certamente dois pecados historiográficos capitais contra os quais muito tem se debatido a historiografia recente: o anacronismo e a simplificação indevida. Tratar um objeto ou processo histórico no âmbito de sua singularidade histórica e de sua complexidade processual é certamente um horizonte permanente a ser perseguido pelos historiadores, e mais ainda pelos historiadores econômicos e economistas que analisam processos históricos. O nosso objetivo neste artigo será o de refletir sobre estes horizontes de trabalho, diante dos quais se devem se colocar necessariamente os historiadores e economistas ao buscar compreender na sua especificidade um determinado sistema econômico historicamente localizado, e a singular "racionalidade econômica" a cada sistema relacionada.

Delimitaremos melhor o conceito de "racionalidade econômica", tal como o estaremos empregando neste conjunto de considerações, no próximo item (seção 2). Mas desde já queremos acrescentar que, além do risco de indevidamente impor a uma sociedade historicamente localizada um modelo somente válido para uma outra época (anacronismo), outro problema a ser considerado é o de que, por mais bem construído que seja um modelo de racionalidade econômica aplicável a um estudo histórico específico a ser realizado, dificilmente este abarcará toda a realidade que o historiador encontra diante de si, através de suas fontes. Ao postularmos um modelo de racionalidade econômica aplicável a uma sociedade histórica, devemos buscar tanto quanto possível a complexidade - ou cuidar para que o modelo dê conta da complexidade das sociedades concretas que serão examinadas. Para isso, é preciso considerar também outros riscos que rondam análise históricoeconômico, para além do anacronismo, tais como a 'ilusão da sincronicidade' - ou seja, a idéia de que em uma determinada economia nacional, por exemplo, todos os fatores progridem ou regridem juntos - ou a "ilusão do modelo globalizador e monolítico", que não considera que as diversas regiões ou sub-unidades espaciais de um mesmo universo considerado (por exemplo, um país como Brasil) podem não se comportar da mesma maneira em uma determinada realidade histórica.

É preciso ainda assinalar que, quando nos referirmos criticamente à idéia de um modelo totalizante, o essencial da crítica estará se dirigindo ao aspecto monolítico de determinados modelos totalizantes e de certas generalizações. Para demonstrar esta parte, analisaremos na quarta seção a evolução da historiografia econômica no Brasil, mostrando como ela vai gradualmente abandonando os grandes modelos monolíticos de análise em favor dos modelos capazes de apreender a complexidade de cada período 
ou espacialidade relacionado à História do Brasil. Exemplificativamente, traremos nesta seção, após um levantamento crítico do desenvolvimento da historiografia econômica no Brasil, os estudos que procuraram apreender a realidade da economia colonial brasileira de modo mais complexo.

\title{
1. Algumas noções iniciais: sistema econômico e racionalidades econômicas
}

Será preciso considerar, antes de mais nada, que o primeiro conceito a ser oportunizado pela história econômica, particularmente para a questão que estaremos discutindo neste texto, é o de "sistema econômico". Tomaremos de empréstimo a definição proposta por Witold Kula - um historiador polonês que é já um clássico tanto entre historiadores como entre economistas historicistas - uma definição bastante rica em torno deste conceito:

\begin{abstract}
"Um sistema econômico é, pois, um conjunto de dependências econômicas reciprocamente ligadas que, pelo fato de estarem vinculadas, surgem mais ou menos ao mesmo tempo e se desfazem, também, aproximadamente no mesmo momento. Datar empiricamente a sua aparição e desaparição é fixar os limites cronológicos de um dado sistema econômico. E elaborar a teoria econômica de um sistema econômico dado é determinar (e ainda empiricamente) a lista mais completa possível das relações de dependência que o mesmo admite e determinar as vinculações recíprocas que fazem deste conjunto de relações um sistema único." (Kula, 1970: 47)
\end{abstract}

Em primeiro lugar, Kula admite falar em um "sistema econômico" como um conjunto maior que integra de maneira coerente certos fatos econômicos que de outra maneira estariam dispersos, ressaltando que este sistema possui uma historicidade definida - esta definida por um conjunto de relações recíprocas que os fatos econômicos de determinado tipo estabelecem entre si. Assim, do mesmo modo que surgem em uma determinada sociedade historicamente localizada estas interações específicas de fatos econômicos, relacionadas a certo padrão que pode ser identificado e decifrado por historiadores e economistas, estas relações se desfazem a certa altura. Vale dizer, um sistema econômico não é uma realidade nem estática e eterna - ele, de um lado, apresenta uma dinamicidade própria e uma tendência a se transformar; e, de outro lado, as transformações podem conduzi-lo, a certa altura, a adquirir uma outra identidade que já pouco tem a ver com a situação inicial do sistema. Em uma palavra, um "sistema econômico" possui uma historicidade.

Os alertas e conselhos implícitos na definição proposta por Kula são bem evidentes: o historiador só deve elaborar a teoria geral que lhe permitirá 
examinar determinada realidade econômico-social depois de estudados os casos concretos, e não o contrário. Sobretudo, mostra-se aqui fundamental a idéia de que é preciso construir a "teoria" dos diversos sistemas econômicos a serem analisados - porque não há um só, como de resto propõem algumas correntes da história econômica que buscam transplantar uma determinada racionalidade econômica que é típica do capitalismo mesmo para sociedades pré-industriais.

É contra este tipo de anacronismo muito específico, por vezes pouco percebido por economistas de algumas correntes específicas que se dispuseram a estudar a história econômica, que Maurice Godelier, em um alerta bastante similar ao de Kula, pretende contrapor a idéia de que cada sociedade produz a sua própria racionalidade econômica, não sendo esta diretamente aplicável ou mesmo válida em relação a uma outra sociedade no tempo e no espaço. Godelier nos traz um exemplo muito esclarecedor ao dar a perceber que a motivação de "maximizar a produção e minimizar os custos" somente tem algum sentido no âmbito de uma "hierarquia de necessidades e valores que se impõem aos indivíduos no seio de determinada sociedade e que têm seu fundamento na natureza das estruturas desta sociedade" (Godelier, 1967: 303). Ou seja, a racionalidade típica da economia capitalista não é de modo nenhum transplantável para as sociedades pré-industriais, ou mesmo para outras espacialidades já no período moderno porém mais afastadas do capitalismo europeu.

Aprofundemos a compreensão do conceito de racionalidade econômica, tal como ele estará sendo considerado aqui, de modo a favorecer uma adequada percepção da questão que está sendo colocada e também de modo a proporciona ruma compreensão mais rica de alguns exemplos que serão trazidos para esclarecimento da questão proposta.

Uma racionalidade econômica não existe ou não existiu como algo dado, que pairava como uma diretriz impositiva sobre determinada sociedade no tempo. A racionalidade econômica é uma construção do historiador ou economista para entender determinada sociedade, particularmente no que se refere aos seus aspectos econômicos e a outros que interferem ou interagem com a economia. Por outro lado, esta racionalidade econômica que vai sendo construída pelo historiador deve se basear na apreensão da vida econômica de uma sociedade através dos registros e indícios trazidos pelas fontes, buscando uma aproximação capaz de perceber o essencial e o predominante que podem ser percebidos naquela sociedade. A racionalidade econômica é construída na interação entre o pesquisador-pensador e o seu objeto de estudos.

Vamos entender uma racionalidade econômica, já considerando a sua possibilidade de interação com uma sociedade historicamente localizada que está sendo examinada, como o padrão de comportamentos, pensamentos e sensibilidades que predominam em uma sociedade ou grupos no interior desta 
sociedade relativamente aos aspectos econômicos. Os aspectos econômicos aos quais nos referimos podem ser os modos de interação com o mercado, a circulação, o consumo, a produção da vida material, as formas de ostentação da riqueza, e tantos outros.

Digamos que um pesquisador esteja empenhado em construir ou idealizar uma racionalidade econômica válida para analisar determinada sociedade ou processo histórico. Ele parte da idéia de que "maximizar a produção e minimizar os custos" é uma forma de racionalidade econômica aplicável a esta ou àquela sociedade (ou a todas as sociedades, postura específica que postulamos ser geradora de anacronismos ou de inadequações em diversas situações). Ao examinar determinada sociedade, o pesquisador percebe que a esta sociedade não aprece se aplicar o modelo de racionalidade econômica que tinha em vista. Algo não parece se ajustar, contradições começam a aflorar, exceções mais recorrentes começam a afrontar a possibilidade de se pensar em uma tendência ou regra de acordo com o modelo proposto. Um acordo pode se produzir, em algumas situações, com ajustes na e redefinições na racionalidade econômica proposta. Por exemplo, posso substituir por outro modelo a idéia de que na sociedade em questão, e em outras, sempre se busca "maximizar a produção e minimizar os custos". Se o modelo for ampliado, de modo a apresentar mais abrangência, posso propor a idéia de que toda sociedade tende à "maximização de uma função-objetivo" (seja esta qual for: lucro, prestígio, utilidade ou outras). A ampliação ou flexibilização de um modelo - ou a redefinição de uma racionalidade econômica de acordo com a flexibilização deste modelo - pode resolver, conforme veremos em alguns exemplos. Mas pode se dar também que o ajuste precise ser feito de outras maneiras, considerando por exemplo o forte peso que, em determinada sociedade (e não em outra), é apresentado por um certo fator - como por exemplo a religião ou o padrão de atitudes do homem diante da morte. Vejamos alguns casos, como base para estas considerações.

Para já mencionarmos um exemplo relacionado à história econômica brasileira, há um interessante aspecto examinado por João Fragoso e Manolo Florentino com relação a um movimento aparentemente paradoxal que se dá no Rio de Janeiro da passagem do século XVIII para o século XIX (Florentino e Fragoso, 1993: 104-105). Após duas gerações de contínua acumulação no mercado, os dois historiadores brasileiros verificaram uma mudança de atividade econômica em uma parcela bastante significativa das famílias que haviam constituído a elite empresarial mercantil. Estas abandonavam seus negócios e passavam a se dedicar a atividades rurais e rentistas, que eram de modo geral muito menos lucrativas que suas antigas atividades mercantis.

Este paradoxo aparente só pode ser compreendido quando recolocamos no contexto histórico examinado uma adequada racionalidade econômica que possa ser atribuída ao grupo social em análise. Vive-se aqui em uma sociedade na qual a ascensão social aparece diretamente ligada à aquisição de terras e 
cativos, que neste caso são os bens que identificam o prestígio. Desta maneira, um aspecto relacionado à cultura e às relações de sociabilidade é que estaria comandando o deslocamento de atividades econômicas, que se mostraria incompreensível se o analisássemos a partir de uma racionalidade econômica alicerçada na obsessiva busca por lucros tão típica da mentalidade capitalista.

Kula dá-nos diversos exemplos como este para o caso da economia polonesa de períodos mais recuados. Assim, em uma de suas análises dos latifúndios poloneses nos séculos XVII e XVIII, procura demonstrar que o comportamento econômico dos proprietários de terras parecia ser o oposto do que preveria a economia clássica. Quando aumentava o preço de seu principal produto, o do centeio, produziam menos, e quando o preço abaixava, produziam mais. A explicação deste paradoxo também deveria ser encontrada no âmbito da cultura, ou das mentalidades. Os aristocratas poloneses, neste caso, não estavam interessados em lucros, mas em manter um estilo de vida, um status quo, da maneira a que estavam acostumados, e a sua forma de racionalidade econômica os levava a controlar as variações na produção como tentativas de manter uma renda padrão.

Neste como em outros exemplos, Kula mostra como as relações e comportamentos econômicos em sociedades diversas, que não podem ser assimiladas ao modelo capitalista previsto pela economia clássica, se acham atravessadas por fatores diversos que pertencem ao mundo da cultura - entre os quais os mecanismos formadores de identidade de classe, as relações de parentesco, os sistemas de dotes, as estratégias culturais de inclusão ou exclusão social. Para além da indicação de que não há ou não pode ser considerada uma só, mas sim diversas racionalidades econômicas, casos como estes também demonstram que o mundo econômico não pode ser explicado apenas através dos fatos econômicos, sendo esta uma questão igualmente importante a ser considerada.

Gostaríamos de incluir um novo exemplo, uma vez que os dois anteriormente citados poderiam ser resolvidos se o economista-historiador, na construção do seu modelo de racionalidade econômica para os casos considerados, substituísse a idéia de "maximização da produção e minimização dos custos" pela de "maximização de uma função-objetivo". Na idade média, por ocasião da época das cruzadas, diversos membros pertencentes à aristocracia-guerreira abandonavam feudos que prosperavam a familiares ou vassalos, e partiam para uma aventura que era regida em boa parte dos casos pelo fator religioso e também por determinado imaginário cavalheiresco, ainda que também comportasse a possibilidade de conquista de novas terras e riquezas (ao lado dos enormes riscos da empresa bélica que estava sendo proposta).

Outro exemplo, para colocar em relevo a necessidade de perceber as nuances que devem ser conferidas às diversas racionalidades econômicas, refere-se ao papel que este ou aquele aspecto econômico desempenha na constituição de um 
padrão de hierarquia social, em uma ou outra sociedade histórica. Por exemplo, nos tempos modernos, os três grandes âmbitos em que se pode estabelecer uma hierarquia social de qualquer tipo - portanto, os três grandes âmbitos que regem o mundo da desigualdade humana - são a riqueza, o poder e o prestígio (pode-se discutir, ainda, a cultura, no sentido institucionalizado). Mas o que é falar hoje de riqueza? É certamente falar também de propriedade. Estas noções estão entrelaçadas na modernidade capitalista: a riqueza encobre a propriedade, abrangendo-a, mesmo que não se reduzindo a ela. Vale dizer, se toda a riqueza, no mundo moderno, não se expressa necessariamente sob a forma de propriedade, não há como negar que a propriedade é na atualidade uma das formas mais poderosas de expressão da riqueza (dito de outra forma, a riqueza compra a propriedade; é a forma de acesso, por excelência, à propriedade).

Nem sempre foi assim. Na antiguidade da Grécia clássica, por exemplo, riqueza e propriedade eram noções perfeitamente desentrelaçadas. Portanto, os critérios para a avaliação da desigualdade deveriam considerar cada uma destas noções em separado (como espaços diferentes que integrariam a desigualdade no sentido complexo). Na Grécia antiga, a propriedade significava que o indivíduo possuía concretamente um lugar no mundo (na polis), e que portanto pertencia ao mundo político com os consequentes direitos à cidadania (Arendt, 1989: 71). Por isto, a riqueza de um estrangeiro, ou mesmo de um escravo, não substituía esta propriedade que era exclusiva dos cidadãos, e não lhe conferia obviamente um acesso ao mundo político. Percebe-se aqui que o poder entrelaçava-se então com a propriedade, e ambos situavam-se em um espaço de conexões em separado da riqueza. Desta maneira, se quisermos compreender ou postular uma "racionalidade econômica" que melhor exprimisse os pensamentos e sensibilidades de um cidadão grego da Atenas clássica, com relação a determinados aspectos econômicos, precisaremos considerar estes elementos que concernem à definição do próprio conceito de cidadania para os homens daquela época e sociedade.

Voltemos às proposições de Kula. Além de oferecer inúmeros exemplos concretos que ajudam a compreender a singularidade das economias social e historicamente localizadas, Kula mostra não apenas que nos diversos períodos históricos as práticas são distintas, frequentemente contrárias a uma prática e racionalidade capitalista que não pode ser tomada como modelo universal, como também dá a perceber a diversidade de sentidos e conotações que, nestas sociedades, adquirem expressões como "câmbio", "investimento", "consumo" (Kula, 1979: 97). Por outro lado, não se trata de cair no absoluto relativismo. Kula mostra que haveria algumas dimensões inerentes às diversas realidades econômicas que poderiam ser tomadas como aspectos irredutíveis, como por exemplo o fato de que nenhum grupo humano pode sobreviver consumindo mais do que produz ou do que consegue se apropriar de outras realidades produtivas. Uma sociedade que colhe menos que semeia, deve encontrar uma solução que re-equilibre a produção e o consumo sob o risco de sua própria 
sobrevivência. Esta é uma lei que parece pairar acima da diversidade de racionalidades econômicas, ou pelo menos daquelas que podem ser aplicadas às sociedades históricas que sobreviveram por uma extensão de tempo relevante. Existem, portanto, questões importantes a serem compreendidas pelos historiadores, no confronto de certos imperativos associados às dimensões econômicas ou mesmo biológicas com as múltiplas formas de racionalidade econômica, conforme as várias sociedades historicamente localizadas.

A questão das "racionalidades econômicas" merece ser refletida com cuidado, pois não tem sido encarada de forma unânime entre economistas e historiadores no decurso da história da história econômica. Teremos aqui duas questões interligadas: de um lado a indagação acerca da universalidade ou não de uma possível teoria sobre os desenvolvimentos econômicos; de outro, uma antiga questão a qual devem se preocupar todos os historiadores, sejam os associados à história econômica ou a outras modalidades historiográficas - a questão do 'anacronismo'.

Estes problemas básicos aparecem amiúde quando o historiador toma a si a tarefa de levantar e analisar economicamente os fatos relativos a uma sociedade cujos próprios critérios para constituição de uma massa de dados estão presos a uma especificidade temporal, diferindo particularmente dos critérios que presidem a própria realidade econômica do historiador. Em uma palavra, alguns problemas começam a surgir quando o historiador impõe a si a tarefa de fazer uma análise econômica retrospectiva.

O problema não é novo, pois ele tem tocado tanto os historiadores econômicos como, antes deles, os economistas históricos (isto é, aqueles que partem da formação de economistas para empreenderem uma análise econômica de períodos do passado). As atitudes básicas, de um lado ou de outro, oscilam neste caso entre duas posições extremas, admitindo inúmeras intermediações e posicionamentos teórico-metodológicos. Em um extremo estariam os historiadores e economistas que partem de uma teoria econômica em seu estado atual, tomada aqui como universal (isto é, aplicável a todas as sociedades e sistemas econômicos de modo absoluto). No outro extremo estaria esta posição que poderia configurar um relativismo radical: aquela que considera que cada sistema econômico tem suas leis próprias (ou, dito de outra forma, parte-se aqui do pressuposto de que os mecanismos econômicos são distintos em cada sistema). A primeira posição pode ser representada pelos economistas de Chicago da década de 1930, articulados em torno de Earl Jefferson Hamilton. A outra encontra sua representação mais amiúde entre os historiadores, ou entre os economistas que se fizeram historiadores em meio à torrente de estímulos por uma renovação historiográfica desde os anos 1930, sendo que dela pode ser dado como um nome bastante representativo o de Ernest Labrousse. 
Hamilton queria aplicar ao estudo de todas as economias do passado a teoria econômica em seu estado atual, ou seja, produzida na e pela sociedade regida pela economia capitalista da sua época. Haveria, nesta maneira de ver, uma teoria econômica que em tese seria aplicável para sociedades tão diversificadas no espaço e no tempo como todas aquelas da Europa situadas entre o século XVI e o século XX, mesmo que de fato se relacionem a nuances distintas dentro do capitalismo, como o capitalismo comercial (patrimonial ou anônimo) ou como o capitalismo industrial (patrimonial, anônimo, financeiro, tecnocrático, apenas para citar algumas variantes). Já nem tocaremos na questão ainda mais delicada que concerne às economias da Antiguidade clássica e dos períodos medievais.

Os historiadores, de modo geral, reagiram ou têm reagido mais enfaticamente a posições como esta que advoga a universalidade de uma moderna teoria econômica, e estas críticas incluem nomes que vão desde Pierre Vilar (1982) ${ }^{2}$ até Jean Meuvret (1987) ou o próprio Labrousse (1979)3. Este último, por exemplo, em célebre estudo sobre as crises do antigo regime econômico (Labrousse, 1932), apresentou como pedra de toque para uma aproximação verdadeiramente consciente do problema o fato de que, se as crises cíclicas do capitalismo industrial são crises de superprodução industrial, já as crises do Antigo Regime são sempre crises de subprodução agrícola (seu universo de análise, no caso, é a França da época).

Haveria também estádios intermédios entre as posições da 'teoria econômica de validade absoluta' e a 'teoria do relativismo econômico' de acordo com cada sociedade histórica. Pode-se, por exemplo, advogar que - embora não haja um sistema econômico ou uma teoria a ser exportada na sua integralidade para todos os períodos anteriores - existiriam certos mecanismos fundamentais que a princípio apareceriam para o caso de todas as sociedades, ou pelo menos para um grande número delas. Esta tendência também apareceu com os economistas de Chicago, mas a partir da década de 1950, tendo entre alguns de seus nomes mais remarcáveis os de Milton Friedman e Oskar Lange (o primeiro expôs suas idéias nos seus Ensaios de Economia Positiva) (Friedman, 1953). A idéia matriz que anima esta posição intermediária é precisamente a de que existiriam certos mecanismos fundamentais concernentes a determinadas variáveis que deveriam ser o objeto de estudo do historiador econômico. Ainda que, em relação a sistemas mais complexos, estes mecanismos fundamentais sejam capazes de combinar-se em proporções variáveis e diversificadas, seria possível descobrir estes funda-mentos, e nisto consistiria a tarefa do historiador econômico ou do economista historiador.

2 Além da obra citada, para considerar um estudo mais específico deste historiador, ver: (Vilar, 1980).

3 Além da obra citada, para considerar os estudos mais específicos de Labrousse, ver: (Labrousse, 1944) e (Labrousse, 1932). 
Discute-se, por exemplo, o fundamento da tendência pressupostamente presente na maior parte das sociedades de obter a chamada "vantagem máxima", o que consistiria em uma determinada atitude que se faz constante tanto em sociedades capitalistas desenvolvidas como sub-desenvolvidas. Existiriam fundamentos que se relacionam com a tecnologia (a produção do ferro necessita de determinada quantidade de carvão), ou com as técnicas contábeis (os balanços da contabilidade clássica resistem ao tempo).

Poder-se-iam discutir fundamentos mais ou menos universais para modelos econômicos de um mesmo tipo (ou seja, fundamentos que se aplicassem a todas as sociedades submetidas ao padrão capitalista, por exemplo, independentemente do recorte espacial ou cronológico dentro do capitalismo). Aqui se enquadraria, no caso, a atrás citada lei da procura do lucro máximo, que poderia ser validável para todas as sociedades capitalistas (embora não pudesse ser verificada para as sociedades medievais). É a possibilidade de discutir fundamentos mais ou menos perenes como estes que habilitaria falar naquilo que François Perroux chamou de "ciência econômica generalizada"4. O importante para o historiador, naturalmente, seria trabalhar com a consciência dos limites de sua generalização (cada tipo de fundamento pode implicar em uma aplicabilidade relativa a um âmbito ou universo menos ou mais extenso).

As posições atrás - referidas com relação à universalidade possível ou à relatividade radical de toda teoria econômica - apenas ilustram o terreno pantanoso que, ainda no campo das tomadas de posição conceituais, o historiador econômico precisa enfrentar ${ }^{5}$. Abordar os aspectos econômicos da história não pode significar apenas um trabalho de coleta quantitativista. Este tipo de trabalho, para não recair na coleta anacrônica de fatos econômicos do passado, deve estar vinculado a uma posição que é também filosófica, teórica, metodológica.

\section{Outros riscos a serem contornados nas análises econômicas históricas}

Devemos mencionar, ao passo em que discutimos a relação entre um sistema econômico e a sua forma de "racionalidade econômica", alguns dos riscos mais graves contra os quais devem se prevenir os historiadores econômicos. O primeiro deles, já mencionado, é aquele que ronda o trabalho de todos os historiadores, nas diversas modalidades da história: o anacronismo. Em História Econômica, o principal tipo de anacronismo - fundador de todos os outros - é o de importar indevidamente para uma determinada sociedade

4 Acerca das generalizações possíveis de serem consideradas para as sociedades capitalistas, ver os desenvolvimentos propostos em Perroux, 1937. Relativamente ao recorte do capitalismo avançado, ver: Perroux, 1967.

5 Para um balanço mais detalhado das posições que atrás descrevemos, ver: Mauro, 1969: 44-51. 
historicamente localizada um sistema ou uma racionalidade econômica que bem se aplicam às sociedades de nosso tempo, mas que mal se ajustam a outras sociedades historicamente localizadas. Já discutimos como a racionalidade econômica típica do mundo capitalista, enquanto modelo de comportamento para os fatos econômicos a serem examinados, pode não ter nenhuma congruência em relação ao mundo histórico que o historiador está examinando. Assim, nada implica em que a 'obsessão pela busca do lucro' seja um fator que vá ditar as normas em todas as sociedades ou situações históricas.

Também seria oportuno mencionar o risco da "ilusão da sincronicidade" - ou seja, a idéia de que em uma determinada economia nacional, por exemplo, todos os fatores progridem ou regridem juntos. Os fatores integrados em um determinado sistema econômico podem ter cada qual o seu ritmo próprio. De maneira análoga, as diversas regiões ou sub-unidades espaciais de um mesmo país podem não se comportar da mesma maneira em uma determinada realidade histórica: a economia das pequenas unidades pode apontar, eventualmente, para especializações econômicas e desenvolvimentos diferenciados. O historiador, aqui, deve estar pronto para se afastar da 'ilusão do modelo globalizador único', da generalização que busca submeter indevidamente todas as regiões e práticas inseridas em uma determinada sociedade, como ocorreu na historiografia brasileira de certa época, por exemplo, com a generalização de um modo de produção escravistacolonial baseado quase que totalmente em uma monocultura exportadora, sem considerar seja as especificidades de cada região, seja os mercados internos ou as interações entre os elementos internos da economia colonial da América portuguesa. Neste caso, a louvável tentativa de entender a história econômica brasileira como uma totalidade - típica de uma historiografia que vai desde Caio Prado Júnior nos anos 1930 até Ciro Flamarion Cardoso e Jacob Gorender em tempos mais recentes - terminou por se confrontar com limites que só seriam contornados pelas teses de pós-graduação brasileiras que começam a surgir nas últimas décadas do século XX, voltadas para as realidades locais dos períodos colonial e imperial.

Estes, enfim, são os riscos teóricos da história econômica: totalização sem apoio empírico, reducionismos vários. Por outro lado, para já nos referirmos a algumas técnicas presentes no trabalho de história econômica, particularmente à quantificação, poderemos discutir outros riscos. O primeiro deles é o que poderia ser chamado de "fetiche da quantificação', a saber, a quantificação por ela mesma, não como meio mas como fim. Uma história econômica que se limite descritivamente a enunciar informações quantificadas seria análoga, na história narrativa, à mera factualidade. Uma curva de preços não pode ter valor por si mesma. Ao contrário, seu valor estaria em servir para uma interpretação histórica que a considerasse como material de análise, e não como finalidade a ser atingida. Ernst Labrousse, um dos pioneiros da quantificação na história, postulava que a quantificação, destinada a desvelar 
uma determinada realidade conjuntural, deveria contribuir para a realização de uma história total que esclarecesse a dinâmica das estruturas, das crises sociais e institucionais, e assim por diante. Quando ele elaborava uma curva de preços, tinha em vista compreender uma realidade sócio-econômica mais complexa, para cuja compreensão a curva de preços funcionaria como um sinalizador privilegiado.

Esta postura, de fundar toda uma explicação histórica complexa apenas no trabalho quantitativo - ou, mais ainda, em um único aspecto quantificado pode eventualmente conduzir a um problema diverso: o da 'supervalorização da quantificação'. Acreditar por exemplo que uma curva de preços pode dar conta da explicação de todo um desenvolvimento histórico-social, sem o concurso de outros fatores e recursos historiográficos, pode produzir resultados tão questionáveis quanto a mera descrição quantitativa.

\section{A busca de singularidades e racionalidades econômicas específicas na História do Brasil}

Nesta seção, gostaríamos de trazer alguns exemplos relacionados aos vários problemas especificados, e já relativos à história do Brasil. Desde já é preciso lembrar que, no Brasil, a história econômica tem sido desde os anos 1930 um campo bem frequentado pelos historiadores, de modo que será útil pontuar algumas contribuições importantes para este campo de estudos antes de adentramos a questão que mais nos interessa neste momento, que é a do deslocamento da busca de modelos generalizantes para estudos atentos às especificidades e singularidades. Os objetos e interesses de estudo, desde aquela época, se diversificam consideravelmente. Mencionaremos inicialmente, ao lado de outras temáticas, o lugar especial que ocuparam as tentativas de elaborar modelos econômicos globais, que dessem conta de entender a história econômica brasileira como uma totalidade. Surgiram então grandes modelos explicativos para a realidade da América portuguesa, para a sociedade escravista-colonial, para a economia no Estado Novo ou no período desenvolvimentista, através de autores que vão de Caio Prado Júnior (1977), um pioneiro na área, até historiadores, economistas ou sociólogos como Fernando Novais (1979), Celso Furtado (1976), Ciro Flamarion Cardoso (1973), Jacob Gorender (1978). Por outro lado, este mesmo grande período situado entre os anos 1930 e 1970 nos mostra um contraponto bastante importante, no qual alguns historiadores se esmeram na atenção às singularidades locais e as complexidades internas do sistema econômico examinado. Trata-se de um contraponto importante, para utilizar aqui a metáfora musical, que logo assumiria o papel da melodia principal no que concerne aos estudos de história econômica no brasil. 
Com relação a esta importante linha de contraponto, pode-se dizer que um balanço inicial da história econômica no brasil certamente estaria incompleto sem a referência a Alice Piffer Canabrava (1911-2003) - uma historiadora preocupada, desde os primórdios de sua produção, em atentar para as singularidades dos processos e contextos econômicos relacionados às várias espacialidades e temporalidades da história do Brasil. Canabrava pode ser mesmo considerada uma das fundadoras da moderna historiografia econômica no Brasil - particularmente com seus estudos pioneiros sobre a economia colonial Brasileira - e ao mesmo tempo uma das organizadoras institucionais desta modalidade no Brasil. De fato, a historiadora foi por um lado responsável pela introdução da história econômica na USP, tanto a partir de seu trabalho como professora da disciplina História Econômica Geral do Brasil (a partir de 1947), como através de sua atuação como diretora da Faculdade de Economia e Administração entre 1954 e 1957. De outro lado, a historiadora logo apareceria como sócia-honorária da ABPHE (Associação Brasileira dos Pesquisadores em História Econômica), desde a criação desta entidade que se constitui na associação representativa dos historiadores econômicos brasileiros.

O pioneirismo de Canabrava - e neste ponto já nos referimos à sua especial atenção às singularidades locais e à complexidades - começa a aparecer já desde a defesa de sua tese para catedrática em História Econômica da USP, intitulada "O desenvolvimento da cultura de algodão na Província de São Paulo: 1861-1875” (1951). Aqui já podemos identificar a sinalização de preocupações que, conforme veremos, somente se intensificarão a partir dos anos 1970 e 1980 com a eclosão de importantes estudos locais que permitirão redimensionar as obras mais generalizantes sobre a economia brasileira ${ }^{6}$.

Uma contribuição análoga, e também constitutiva desta linha de trabalho que, desde tempos mais recuados da historiografia econômica brasileira, já se preocupava em atentar para as especificidades locais e para a complexidade dos sistemas econômicos - dito de outra forma, para a identificação de racionalidades econômicas específicas a cada caso - é a de Eulália Maria Lahmeyer Lobo, historiadora que se ocupou particularmente da América hispânica, mas também do América portuguesa (sobretudo a partir de uma perspectiva comparatista), e de estudos mais específicos sobre o Rio de Janeiro (1978)7.

6 Textos clássicos de Alice Canabrava podem ser encontrados na coletânea História Econômica - estudos e pesquisas, publicada pela UNESP (Canabrava, 2005). Entre estes, destacaremos os textos sobre "A grande propriedade rural” (1) e sobre "Manufaturas e indústrias no período de D. João VI no Brasil” (2), para ressaltar os que se referem à História Econômica brasileira como um todo, para além dos ensaios mais específicos sobre a História Econômica do Estado de São Paulo. Também produziu trabalhos de profundo interesse para o estudo, ensino e pesquisa da História Econômica no Brasil ao refletir sistematicamente sobre as fontes primárias disponíveis ao historiador econômico: (1) "Fontes primárias para o estudo da moeda e do crédito em São Paulo no século XVI" (1948) e (2) "Fontes primárias sobre o escravismo" (incluída em Canabrava, 2005).

7 Tal como Alice Canabrava, Eulália Lobo buscou ainda refletir sistematicamente sobre as fontes primárias disponíveis para a História Econômica, a exemplo do artigo "Fontes para a história do Comércio da cidade do Rio de Janeiro" (1998). 
Antecipando uma atenção direcionada à complexidade das trocas comerciais do Rio de Janeiro colonial e, mais particularmente, à importância do comércio interno colonial - temática que se afirmaria com maior intensidade nos anos 1980 - a historiadora foi pioneira no que se refere a um olhar em maior detalhe acerca dos negociantes de grosso trato, além de dominar amplamente os usos historiográficos da quantificação e serialização de modo a investigar a história dos preços no Rio de Janeiro (1971) ${ }^{8}$. Por outro lado, aberta a diversificações as mais diversas no que concerne a metodologias e usos de fontes, foi também exímia analista de fontes históricas de uma perspectiva qualitativa, o que se exemplifica com sua análise intensiva da correspondência de um imigrante português da passagem do século XIX ao XX, com vistas a recuperar uma história de vida de modo a iluminar aspectos relacionados à história mais ampla do comércio e da vida urbana no Rio de Janeiro9.

Seria oportuno lembrar também o pioneirismo de Eulália Lobo na prática de uma história econômica comparada, o que se dá desde cedo com a sua tese intitulada "Administração Colonial Luso-Espanhola nas Américas" (publicada em 1952), na qual contrasta sistematicamente a história políticoadministrativa portuguesa e espanhola nas duas áreas coloniais. Em uma época na qual predominava a tendência de tratar o Brasil isoladamente, este trabalho mostra-se particularmente significativo. Para além disto, seria possível citar inúmeros trabalhos que revelam um raro espírito de experimentação, acrescentando contribuições únicas à história econômica brasileira. Tal seria o caso do estudo sobre os Caminhos de Chiquitos às Missões Guaranis (1960), uma estrada ligada à história do Paraguai, Bolívia e Brasil, e em cuja documentação tornam-se perceptíveis diversos conflitos envolvendo estes três países e também os Estados Unidos.

Será oportuno destacar, na linha de autores que procuram se cedo procuraram se contrapor ao modelo mais generalizante e redutor de um sistema colonial essencialmente direcionado para a Metrópole (Novais, 1983), a análise empreendida por José Roberto do Amaral Lapa sobre O Antigo Sistema Colonial (1973 e 1991), e também suas obras voltadas para a história econômica local, entre as quais se destaca A Bahia e a Carreira da Índia, tese de doutorado publicada pela primeira vez em 1968 e que examina em detalhe

8 Ver, em especial, o artigo Evolução dos preços e do padrão de vida no Rio de Janeiro, 1820-193o (Lobo, 1971), e também o estudo mais amplo sobre História do Rio de Janeiro - do Capital Comercial ao Capital Industrial e Financeiro (Lobo, 1978). Sobre o estudo de comerciantes locais, seria oportuno citar a tese de Eulália Lobo para o concurso de professora catedrática, que examinou os Consulados, órgãos representativos dos comerciantes espanhóis, em um trabalho intitulado "Aspectos da atuação dos consulados de Sevilha, Cádiz e da América Hispânica na evolução econômica do século XVIII”. Aqui, aparece particularmente o interesse em investigar o surgimento do comércio colonial interno, e o fortalecimento dos consulados locais apresenta-se como uma brecha importante no que se refere ao relacionamento da América Hispânica com a metrópole absolutista.

9 Referimo-nos à pesquisa sobre o imigrante Antonio Dias Leite, que por ser familiar da historiadora possibilitou a esta a constituição de um conjunto importante de fontes, sobretudo as cartas dirigidas à sua esposa Georgeta Furquim Lahmeyer (Lobo, 2005 e 2006). 
a escala das naus da Índia nos portos do Brasil ${ }^{10}$. A Carreira da Índia realizava a ligação comercial entre Lisboa e Goa, na Índia, cruzando em ida e volta o Atlântico e o Índico e realizando escala em Salvador (mais tarde no Rio de Janeiro). Além do intenso intercâmbio de produtos diversos, apresentavase aqui a oportunidade para um rico intercâmbio de "idéias, técnicas, usos e costumes”, para utilizar as próprias palavras do historiador (Lapa, 1968:18). Nesta e em outras de suas obras direcionadas para localidades específicas - Bahia, Mato Grosso, Grão-Pará - Amaral Lapa enfatiza a importância fundamental do mercado interno, ressaltando que este e o mercado externo não são excludentes, tal como tende a propor Fernando Novais (1979).

Ao lado das importantes contribuições de Alice Canabrava, Eulália Lobo e Amaral Lapa para uma história econômica atenta às especificidades e complexidades locais, estas já antecipando a preocupação em examinar as trocas internas e o dinamismo singular da economia colonial, deve-se destacar que a linha de estudos econômicos que começa a adquirir importante projeção desde os anos 1930 foi precisamente aquela que passaria a atentar para as grandes generalizações e para a busca de grandes modelos explicativos para a história econômica brasileira, a começar pelo modelo proposto por Caio Prado Júnior em torno dos fundamentos básicos do materialismo histórico e com destaque para o esforço posterior de Jacob Gorender, já nos anos 1970, em definir e especificar um modo de produção escravista-colonial. Assim, já Caio Prado Júnior, com sua basilar obra de 1942 sobre A Formação do Brasil Contemporâneo (1981), buscava enxergar o Sistema Colonial a partir de uma ênfase na exportação, iniciando um modelo de análise que daria as linhas mestras de toda uma historiografia ecoômica direcionada para o estudo deste período:

\footnotetext{
"Se vamos à essência da nossa formação, veremos que na realidade nos constituímos para fornecer açúcar, tabaco, alguns outros gêneros; mais tarde ouro e diamantes; depois, algodão, e em seguida café, para o comércio europeu. Nada mais que isto. É com tal objetivo, objetivo exterior, voltado para fora do país e sem atenção a considerações que não fossem o interesse daquele comércio, que se organizarão a sociedade e a economia brasileiras. Tudo se disporá naquele sentido: a estrutura, bem como as atividades do país" (Prado Jr, 1981: 32)
}

A economia colonial - o modo de produção do Brasil escravista no período colonial - é apresentado de modo unilateral, voltado para fora e em uma perspectiva totalizante. A economia brasileira da época é agro-exportadora, "nada mais que isto". Deste modo, os grandes modelos explicativos inaugurados por Caio Prado Jr., fundamentais na história da historiografia econômica brasileira, concentravam sua riqueza de contributos em uma visão mais generalizadora, e não tardariam a serem confrontados por trabalhos mais

10 Amaral Lapa também foi um importante analista da Historiografia Brasileira (1972 e 1976). Também são importantes as suas obras mais gerais, como A Economia Cafeeira (1998) e História econômica da independência e do Império (1996). 
específicos, atentos às singularidades locais. Ciro Flamarion Cardoso (1973) e Jacob Gorender (1978), ainda que preocupados em estabelecer grandes modelos explicativos que dessem conta da sociedade colonial, já empreendem uma crítica à perspectiva de Caio Prado Júnior no sentido de que esta centrava a análise na 'circulação', e não na 'produção', e é destes historiadores a autoria da expressão "modo de produção escravista colonial”. Ainda assim, a história econômica no Brasil ainda teria de esperar por uma atenção mais direcionada às singularidades locais e às complexidades relacionadas ao dinamismo interno do sistema colonial.

As últimas décadas do século XX assistem precisamente à eclosão de trabalhos mais monográficos, interessados em perceber através de investigações locais - muitas vezes com o apoio da História Serial - precisamente aquelas especificidades e complexidades que os grandes modelos explicativos deixavam escapar, por vezes em fórmulas ou modelos reducionistas. Estaremos exemplificando com os estudos relacionados a um problema histórico bastante específico - o da economia colonial brasileira - através do qual foi confrontado o antigo modelo da monocultura agro-exportadora direcionada única ou preponderantemente para o mercado externo ${ }^{11}$, e na qual o escravo desempenhava um papel específico em um tipo de unidade produtiva e de hierarquia que parecia favorecer a visão dicotomizada acerca das posições entre Senhores e escravos ${ }^{12}$. As investigações ao nível regional permitiram que se verificassem inúmeros fatores significativos, tais como a importância do mercado interno, a eventual diversificação de culturas, o papel dos homens livres pobres na economia e na sociedade escravocrata ${ }^{13}$, as estratégias de negociação dos escravos no interior da sociedade que os oprimia e do sistema econômico que os incorporava como força de trabalho ${ }^{14}$. Para além disto, estas mesmas monografias também revelaram toda uma diversidade inter-regional que os grandes modelos econômicos explicativos nem sempre previam.

\footnotetext{
11 Em um artigo de 1985 no qual analisa a economia mineira da segunda metade do século XIX, Robert Slenes chama atenção para a diversificação econômica daquela região, para a produção de gêneros voltada para o mercado interno, e para o dinamismo da economia não-exportadora (Slenes, 1985). De igual maneira, no âmbito de pesquisas que evidenciam a diversificação da economia colonial, podemos citar, entre outros, o trabalho de Hebe Castro, que, ao analisar um município fluminense do século XIX, pôde perceber para os maiores produtores locais uma diversificação de produção voltada para o mercado local (Castro, 1987).

12 Assim, por exemplo, a tese de Mary Karasch sobre a vida dos escravos no Rio de Janeiro (1988) já chama atenção para a presença importante de pequenos senhores que, na sociedade escravocrata, possuíam apenas um ou dois escravos, o que permitia confrontar o modelo dicotômico que aos escravos opunha apenas o grande latifundiário proprietário de inúmeros escravos, ignorando todo um contingente de pequenos senhores (Karasch, 2000). Pesquisas como esta, e também a de Stuart Schwartz para o Recôncavo Baiano, confrontavam a idéia de que a propriedade escrava apresentava-se radicalmente concentrada no nas mãos de grandes proprietários de terras (Schwartz, 1983).

13 Uma referência já clássica para este aspecto é a obra de 1969 produzida por Maria Sylvia de Carvalho Franco sobre os Homens Livres na Ordem Escravocrata (1994), certamente um trabalho pioneiro que já chamava atenção para uma questão que seria cada vez mais abordada nas décadas seguintes.

14 A esse respeito, tem-se um marco importante com o livro Campos da violência de Sílvia Lara (1988). Mais ainda, é fundamental a referência à obra conjunta de João José Reis e Eduardo Silva (2005) intitulada Negociação e conflito: a resistência negra no Brasil escravista.
} 
Desta lavra, e das décadas seguintes - e a menção de trabalhos aqui terá apenas valor exemplificativo - são alguns dos mais importantes trabalhos sobre a economia brasileira nos seus períodos históricos, e não apenas no que concerne ao período colonial. Destacam-se desde as investigações regionais ou mais localizadas sobre o período escravocrata, como a obra de Kátia Matoso intitulada "Bahia: a cidade de Salvador e seu mercado no século XIX" (1978), ou a obra de Douglas Libby sobre a "Transformação e Trabalho em uma economia escravista - Minas no século XIX” (1988), até as investigações de recorte mais extenso sobre o processo de industrialização brasileiro, como a pesquisa de Wilson Cano sobre as "Raízes da Concentração Industrial” (1981), a obra de Geraldo Beauclair sobre o mesmo tema ("Raízes da Indústria no Brasil”, 1992), ou os trabalhos de Maria Bárbara Levy acerca de diversos aspectos relacionados à história econômica da cidade do Rio de Janeiro, entre os quais a História da Bolsa de Valores (1977), o desenvolvimento das atividades bancárias no Rio de Janeiro no século XIX (1979), e ainda sobre a industrialização do Rio de Janeiroe seu papel no desenvolvimento da indústria nacional $(1994)^{15}$.

No âmbito dos estudos sobre a Escravidão ou ambientados na Economia Colonial, a massa crítica de trabalhos regionais e a possibilidade mais concreta de lançar mão da História Serial passou a permitir também novas visões de conjunto, mais fundamentadas e sem os reducionismos das generalizações anteriores aos anos 1970. Aparecem aqui obras importantes como o estudo de João Fragoso e Manolo Florentino intitulado "Arcaísmo como Projeto" (1993), e o estudo de João Fragoso (1998) sobre a economia local do Rio de Janeiro que, conforme veremos adiante, avança pela trilha que começara a ser percorrida por autores como Kátia Mattoso nos anos 1970 e $1980^{16}$.

A título de exemplo, examinaremos alguns desenvolvimentos historiográficos em torno da temática da economia colonial, mostrando como foi precisamente um olhar mais atento para a realidade local, alicerçado em sistemáticas pesquisas empíricas, o que permitiu uma verdadeira revisão dos modelos generalizantes que, antes dos anos 70, vinham sendo elaborados para a compreensão da economia brasileira no período colonial. Ao lado do já mencionado trabalho de Kátia Mattoso sobre a Bahia, traremos o exemplo de uma obra que representa certamente um marco para a historiografia econômica brasileira mais recente: o estudo de João Fragoso intitulado "Homens de Grossa Aventura - acumulação e hierarquia na praça mercantil do Rio de Janeiro, 1790-1830” (1998). Esta obra, como a de Kátia Mattoso e outras, permitiu precisamente à nova historiografia econômica brasileira examinar os ritmos internos da economia colonial, suas assincronias

15 Contrastando com o citado trabalho de Wilson Cano acerca das origens da industrialização no Brasil, Maria Bárbara Levy apresenta uma leitura distinta, considerando que o primeiro centro industrial do Brasil teria sido o Rio de Janeiro, somente suplantado por São Paulo a partir de 1920.

16 O livro Homens de grossa aventura, de João Fragoso (1998) é parte de sua tese de doutoramento, assim como o livro Arcaísmo como Projeto (1993) resultou da compactação de resultados dessa mesma tese e da tese de doutoramento defendida por Manolo Florentino. 
em relação ao mercado internacional, suas diversidades regionais, suas complexidades irredutíveis ao desgastado e generalizador modelo que retratava a economia colonial como um sistema exclusivamente escravistaagro-exportador, diretamente dependente dos centros europeus ${ }^{17}$.

Objetivando examinar as formas de acumulação que perpassam a economia colonial brasileira em fins do século XVIII e primeiras décadas do século XIX, Fragoso elege como lócus privilegiado de observação o funcionamento do mercado do Rio de Janeiro e suas formas de produção. Mas, sobretudo, o que aqui se empreende é mais uma contribuição à vigorosa crítica em relação aos antigos modelos explicativos da economia colonial brasileira, alcançada através da exposição de uma série de novas complexidades que se tornam bastante claras a partir de uma bem fundamentada pesquisa empírica amparada em análises seriais de uma vasta documentação.

A primeira complexidade a ser examinada é a de que a economia colonial brasileira apresenta através dos números levantados um complexo jogo de ajuste e desajuste em relação ao ciclo econômico internacional. Ao invés de uma economia inteiramente atrelada ao ritmo internacional, o autor vem mostrar que - ainda que esta sintonia se expresse em algumas oportunidades - a economia colonial brasileira também tem seus ritmos próprios.

A consciência de que os ritmos coloniais não se ajustam inteiramente e em todos os momentos às tendências internacionais já vinha sendo expressa através das pesquisas de Kátia Mattoso, que examinara através de uma sistemática metodologia quantitativa os preços na Bahia do mesmo período, demonstrando seu comportamento de acordo com ritmos próprios (Mattoso, 1973: 167-182). Assim, enquanto os preços europeus haviam sofrido uma inflexão geral "para cima" entre 1810 e 1815, até atingir neste ano a crise mundial que inaugura uma fase depressiva, esta inflexão só ocorreria na Bahia a partir de 1822 .

O objetivo de Fragoso é seguir nesta mesma trilha: demonstrar que também o Rio de Janeiro tinha seus ritmos próprios. O recorte da pesquisa situa-se no enquadramento de um ciclo de Kondratieff que tem uma "fase A" positiva entre 1792 e 1815, e uma fase negativa (B) entre 1815 e 1850. Contudo, se por um lado verifica-se a sintonia entre uma expansão econômica brasileira e a ampliação do comércio no plano internacional, já para o período seguinte (a fase B) esta sintonia não se verifica. Entre 1815 e 1817, ocorre uma crise mundial que se expressaria sob a forma de uma depressão econômica até 1850, afetando diretamente os preços do açúcar e do algodão.

17 As propostas de Fragoso e Florentino para uma nova interpretação do período, é preciso ressaltar, também têm sido objeto de crítica, no âmbito de uma polêmica que está longe de terminar. Ver, como texto crítico às propostas destes dois autores, o artigo de Mariutti, Nogueról, Danieli Neto, "Mercado interno colonial e grau de autonomia: críticas às propostas de João Luís Fragoso e Manolo Florentino” (2001). Com relação a um texto mais geral sobre estes modelos explicativos, ver o artigo de Rodrigo Alves Teixeira para o volume 36 da revista Estudos Econômicos (2006). 
Conforme a interpretação clássica, a montagem da economia cafeeira apresenta-se como uma resposta ao declínio destes produtos e à conjuntura econômica internacional desfavorável.

O modelo confrontado e criticado pelo autor (e mais especificamente considerando o contexto específico das transformações que se dão na passagem do século XVIII para o século XIX) é o da economia colonial exclusivamente fundada na monocultura exportadora, destinada a fornecer excedentes para as economias centrais européias. Segundo este modelo, não haveria lugar na colônia para um mercado interno suprido por produções locais, nem para possibilidades de acumulações endógenas, e tampouco para ritmos econômicos próprios, desvinculados das economias que dominavam o mercado internacional (Fragoso, 1998: 16-17). Contudo, são precisamente estes aspectos que Fragoso verifica, mostrando por exemplo que o comportamento da economia colonial não pode ser medido apenas pelo desempenho do setor exportador. Assim, contra uma queda de preços de produtos ligados ao setor exportador, como o açúcar branco, Fragoso demonstra uma realidade diferente relativa aos produtos coloniais de abastecimento que desembarcam no porto do Rio de Janeiro (Fragoso, 1998: 20). Sintetizando a questão, o mercado interno colonial produz os seus próprios ritmos, que interagem de muitas maneiras com os ritmos ditados pelo mercado internacional, respondem ou resistem a eles. O mercado interno, portanto, é uma realidade efetiva, importante para a compreensão da história econômica. Conforme as palavras de Fragoso, "a economia colonial é um pouco mais complexa do que uma plantation escravista, submetida aos sabores das conjunturas internacionais" (Fragoso, 1998: 21). É todo um antigo modelo interpretativo, demasiado simplificador, que aqui se questiona. Mais ainda, diante da verificação empírica de uma verdadeira flexibilidade da economia colonial que a permite confrontar-se à queda de preços internacionais e à retração da exportação, Fragoso identifica a possibilidade de realização de acumulações endógenas no espaço colonial, um dos objetivos centrais de seu estudo. Questionam-se, também, as postuladas relações de estrita dependência que, segundo antigos modelos explicativos, estariam necessariamente presentes nas relações da economia colonial com a Metrópole.

Vale ressaltar, por outro lado, que o trabalho de João Fragoso se refere mais especificamente à virada do século XVIII para o século XIX - um período de crise do antigo sistema colonial. Para os três séculos anteriores de colonização da América portuguesa, decerto, o modelo de análise econômica proposto por Caio Prado Júnior e seguido de perto por Celso Furtado e Fernando Novais conserva considerável poder explicativo ${ }^{18}$. De todo modo, as obras de João Fragoso e Kátia Mattoso foram aqui evocadas apenas

18 Ainda sobre as críticas de Fragoso e Florentino sobre o antigo modelo de compreensão da economia do Escravismo Colonial, vale lembrar que, após a primeira edição de Arcaísmo como Projeto lançada pela Editora Diadorim, esta obra de João Fragoso e Manolo Florentino foi posteriormente lançada pela Civilização Brasileira (2003), já trazendo modificações substantivas e que já resultaram de algumas críticas recebidas pelos autores. 
como suporte exemplificativo. Elas constituem sintomas claros de uma historiografia brasileira em pleno desenvolvimento e renovação, que se liberta de modelos fechados e irredutíveis, que busca novas complexidades e que, sobretudo, empreende um trabalho sistemático sobre as fontes a partir do uso de uma metodologia quantitativa e serial que mostra perfeita vitalidade. A História Econômica, particularmente no Brasil, está longe de uma crise. Outras obras poderiam ser citadas, mas estas já podem dar uma idéia da fecundidade deste campo que, mesmo que tenha cedido espaço no conjunto de preferências dos historiadores em favor de outras modalidades em ascensão, permanece francamente atualizado e produtivo.

A história econômica, neste sentido, tem se apresentado como um campo que se renova e atualiza. Desenvolve-se no sentido da complexidade, da superação das visões simplificadas que habitualmente isolam os fatos econômicos de outras dimensões importantes para a história das sociedades como a política ou a cultura. De igual maneira, os historiadores econômicos mostram-se cada vez mais atentos à questão de que em cada período histórico, ou em cada sociedade historicamente localizada, deve-se buscar uma racionalidade econômica própria e específica do período examinado, e não simplesmente transplantar uma racionalidade capitalista para períodos anteriores nos quais esta racionalidade não existia. Avança-se também na superação dos antigos modelos explicativos nacionais monolíticos, à medida que se desenvolvem estudos regionais capazes de esclarecer a singularidade de cada região em um contexto mais amplo.

\section{Referências bibliográficas}

ARENDT, H. (1989). A Condição Humana. Rio de Janeiro: Forense Universitária.

BEAUClaiR, G. (1992). Raízes da Indústria no Brasil. Rio de Janeiro: Studio F \& S Editora.

CANABRAVA, A. (2005). História Econômica: estudos e pesquisas. São Paulo: Universidade Estadual Paulista (Unesp).

CANABRAVA, A. (1948). Fontes primárias para o estudo da moeda e do crédito em São Paulo no século XVI. São Paulo: Instituto de Administração.

CANABRAVA, A. (1951). O desenvolvimento da cultura de algodão na Província de São Paulo: 1861-1875. São Paulo: Indústria Gráfica Siqueira.

CANO, W. (1981). Raízes da Concentração Industrial. São Paulo: T. A. Queiroz.

CARDOSO, C. F. (1973). "Observações sobre o dossier preparatório da discussão sobre o modo de produção colonial” In: PARAIN, C. [org.]. Sobre o Feudalismo. Lisboa: Estampa. 
FLORENTINO, M. \& FRAGOSO, J. (1993). Arcaísmo como Projeto. Rio de Janeiro: Diadorin.

FRAGOSO, J. (1998). Homens de Grossa Aventura: acumulação e hierarquia na praça mercantil do Rio de Janeiro (179o-1830). Rio de Janeiro: Civilização Brasileira.

FRIEDMAN, M. (1956). The quantity theory of money: a restatement (Studies in the quantity theory of money). Chicago: University of Chicago Press.

FURTADO, C. (1976). Formação Econômica do Brasil. São Paulo: Companhia Editora Nacional.

GODELIER, M. (1967). Racionalidad e irracionalidad em la Economia. México: Siglo XXI.

GORENDER, J. (1978). O Escravismo Colonial. São Paulo: Ática.

KULA, W. (1970). Théorie économique du systéme féodal: pour un modèle de l'économie polonaise, XVIe. Paris: Mouton.

KULA, W. (1979). "Da Tipologia dos Sistemas Econômicos”. In: FOURASTIÉ, J. [org.]. Economia. Rio de Janeiro: Editora FGV.

KULA, W. (1973). Problemas y Métodos de la Historia Econômica. Barcelona: Ediciónes Península.

LABROUSSE, E. (1979). Histoire économique et sociale de la France. Paris.

LABROUSSE, E. (1932). Esquisse du mouvement des prix et des revenus en France du XVIII siècle. 2 vol. Paris: Dalloz.

LABROUSSE, E. (1944). La crise de l'économie française à la fin de l'ancien régime e au début de la Revolution. Paris: PUF.

LAPA, J. R. do A. (1968). A Bahia e a Carreira da Índia. Rio de Janeiro: Companhia Editora Nacional.

LAPA, J. R. do A. (1972). "Alguns problemas da atual historiografia brasileira”. Revista do Instituto de Estudos Brasileiros, n. ${ }^{\circ} 11$.

LAPA, J. R. do A. (1973). Economia Colonial. São Paulo: Perspectiva.

LAPA, J. R. do A. (1976). Historiografia Brasileira Contemporânea. Petrópolis: Vozes.

LAPA, J. R. do A. (1996). História econômica da independência e do Império. São Paulo: Hucitec.

LAPA, J. R. do A. (1998). O sistema colonial. São Paulo: Ática.

LAPA, J. R. do A. (2001). Economia Colonial. São Paulo: Perspectiva.

LARA, S. H. (1988). Campos da violência. Rio de Janeiro: Paz e Terra. 
BARROS, J. D. Os sistemas econômicos e suas formas de racionalidade...

LEVY, M. B. (1977). História da Bolsa de Valores no Rio de Janeiro. Rio de Janeiro: IBMEC.

LEVY, M. B. (1998). A indústria do Rio de Janeiro através de suas sociedades anônimas. Rio de Janeiro: UFRJ.

LEVY, M. B. (1979). História Financeira do Brasil Colonial. Rio de Janeiro: IBMEC.

LIBBY, D. (1988). Transformação e Trabalho em uma economia escravista: Minas no século XIX. São Paulo: Brasiliense.

LOBO, E. M. L. (1998). "Fontes para a história do Comércio da cidade do Rio de Janeiro". Boletin de Fuentes: América Latina en la Hilstória Económica, n. ${ }^{\circ}$ 9.

LOBO, E. M. L. (1952). Administração colonial luso-espanhola nas Américas. Rio de Janeiro: Companhia Brasileira de Artes Gráficas.

LOBO, E. (1959-1960). "Caminho de Chiquitos às missões Guaranis de 1690 a 1718 ”. Revista de História, n. ${ }^{\circ} 40$.

LOBO, E. M. L. (2006). "Imigração e História de Vida (trajetória de seu pai, o imigrante Antônio Dias Leite)” In: Usos do Passado: XII Encontro Regional de História ANPUH. Rio de Janeiro: ANPUH.

LOBO, E. M. L. \& MAIA, L. L. L. (2005). Cartas de Antônio Dias Leite (18701952): um olhar sobre uma época de transformação. Rio de Janeiro: Lidador.

LOBO, E. M. L. (1978). História do Rio de Janeiro (do Capital Comercial ao Capital Industrial e Financeiro). Rio de Janeiro: IBMEC.

LOBO, E. M. L. (1971). "Evolução dos preços e do padrão de vida no Rio de Janeiro, 1820-1930”. Revista Brasileira de Economia, vol. 5 (4).

MATTOSO, K. de Q. (1978). Bahia: a cidade de Salvador e seu mercado no século XIX. São Paulo: Hucitec.

MATTOSO, K. de Q. (1973). "Os preços na Bahia de 1750 a 1930". In: L'Histoire quantitative du Brésil de 1800 a 1930. Paris: CIVRS.

MARIUTTI, E. B. \& NOGUERÓL, L. P. F. \& DANIELI NETO, M. (2001). "Mercado interno colonial e grau de autonomia: críticas às propostas de João Luís Fragoso e Manolo Florentino”. Estudos Econômicos, vol. 31 (2).

MAURO, F. (1969). Nova História e Novo Mundo. São Paulo: Perspectiva.

MEUVRET, J. (1987). La Production De Céréales et la Société Rurale. 2 vols. Paris: Ecole Des Hautes Études en Sciences Sociales.

NOVAIS, F. A. (1983). Portugal e Brasil na crise do Antigo Sistema Colonial. São Paulo: Hucitec. 
PERROUX, F. (1937). Capitalisme et communaute de travail. Paris: Librairie du Recueil Sirey.

PERROUX, F. (1967). A economia do seculo XX . Lisboa: Herder.

PRADO Jr, C. (1977). Formação do Brasil Contemporâneo. São Paulo: Brasiliense.

TEIXEIRA, R. A. (2006). "Capital e colonização: a constituição da periferia do sistema capitalista mundial”. Estudos Econômicos, vol. 36 (3).

VILAR, P. (1985). Iniciação ao Vocabulário da História. Lisboa: Sá da Costa.

VILAR, P. (1982). Desenvolvimento econômico e análise histórica. Lisboa: Editorial Presença.

VILAR, P. (1980). Ouro e Moeda na História. São Paulo: Paz e Terra.

Recebido em: 14 de fevereiro de 2011 Primeira resposta em: 07 de junho de 2011 Aceite em: 20 de junho de 2011 